\title{
Article \\ Intermittent Dynamic Compression Confers Anabolic Effects in Articular Cartilage
}

\author{
Amalie Engstrøm ${ }^{1,2,+}{ }^{\oplus}$, Frederik S. Gillesberg ${ }^{1,2,+}$, Solveig S. Groen ${ }^{1,2}$, Peder Frederiksen ${ }^{1}$, \\ Anne-Christine Bay-Jensen ${ }^{1}$, Morten A. Karsdal ${ }^{1}$ and Christian S. Thudium ${ }^{1, *}$ \\ 1 Nordic Bioscience, Biomarkers and Research, 2730 Herlev, Denmark; aen@nordicbio.com (A.E.); \\ frg@nordicbio.com (F.S.G.); ssg@nordicbio.com (S.S.G.); pef@nordicbio.com (P.F.); \\ acbj@nordicbio.com (A.-C.B.-J.); mk@nordicbio.com (M.A.K.) \\ 2 Department of Biomedical Sciences, Copenhagen University, 2200 Copenhagen, Denmark \\ * Correspondence: cst@nordicbio.com; Tel.: +45-4454-7754 \\ + These authors contributed equally to the work.
}

check for updates

Citation: Engstrøm, A.; Gillesberg, F.S.; Groen, S.S.; Frederiksen, P.; Bay-Jensen, A.-C.; Karsdal, M.A.; Thudium, C.S. Intermittent Dynamic Compression Confers Anabolic Effects in Articular Cartilage. Appl. Sci. 2021, 11, 7469. https:// doi.org/10.3390/app11167469

Academic Editors: Paolo Alberton and Emeline Perrier-Groult

Received: 12 July 2021

Accepted: 11 August 2021

Published: 14 August 2021

Publisher's Note: MDPI stays neutral with regard to jurisdictional claims in published maps and institutional affiliations.

Copyright: (c) 2021 by the authors. Licensee MDPI, Basel, Switzerland. This article is an open access article distributed under the terms and conditions of the Creative Commons Attribution (CC BY) license (https:// creativecommons.org/licenses/by/ $4.0 /)$.
Featured Application: This work shows the use of an ex vivo cartilage compression model to assess the effect of combining compressive loading and growth factors on cartilage remodeling.

Abstract: (1) Background: Mechanical loading is an essential part of the function and maintenance of the joint. Despite the importance of intermittent mechanical loading, this factor is rarely considered in preclinical models of cartilage, limiting their translatability. The aim of this study was to investigate the effects of intermittent dynamic compression on the extracellular matrix during long-term culture of bovine cartilage explants. (2) Methods: Bovine articular cartilage explants were cultured for 21 days and subjected to $20 \mathrm{~min}$ of $1 \mathrm{~Hz}$ cyclic compressive loading five consecutive days each week. Cartilage remodeling was investigated in the presence of IGF- 1 or TGF- $\beta 1$, as well as a TGF- $\beta$ receptor 1 (ALK5) kinase inhibitor and assessed with biomarkers for type II collagen formation (PRO-C2) and fibronectin degradation (FBN-C). (3) Results: Compression of cartilage explants increased the release of PRO-C2 and FBN-C to the conditioned media and, furthermore, IGF- 1 and compression synergistically increased PRO-C2 release. Inhibition of ALK5 blocked PRO-C2 and FBN$\mathrm{C}$ release in dynamically compressed explants. (4) Conclusions: Dynamic compression of cartilage explants increases both type II collagen formation and fibronectin degradation, and IGF-1 interacts synergistically with compression, increasing the overall impact on cartilage formation. These data show that mechanical loading is important to consider in translational cartilage models.

Keywords: osteoarthritis; articular cartilage; dynamic compression; bovine explants; type II collagen; fibronectin; translational research

\section{Introduction}

Osteoarthritis (OA) is characterized by progressive deterioration of synovial joint tissues, including articular cartilage, synovium, ligaments and subchondral bone [1]. Synovial joints are load-bearing organs, and the principal function of articular cartilage is to transfer load with a low coefficient of friction [2]. The importance of mechanical loading for cartilage health is reflected in the large body of literature describing how various forms of joint loading exercises alleviate pain and improve function in OA patients [3-5]. Exercise has been reported to be chondroprotective in subjects with- or at risk of developing OA [6-10], and it has been suggested that moderate exercise may prevent or delay OA onset [11]. In line with this, cartilage thinning has been observed under reduced loading conditions, in instances of disuse such as postoperative immobilization or paraplegia [12-15]. Conditions that lead to excessive cartilage loading, such as joint instability or meniscus resection, are, however, detrimental and lead to degenerative changes in cartilage morphology that greatly increase the risk of 
OA [16]. Presently, there are no approved disease-modifying OA drugs (DMOADs) proven effective at restoring cartilage or modifying the progression of structural damage.

Various experimental models of articular cartilage have been used for investigating how compressive loading influences cartilage biology. Articular chondrocytes are mechanosensitive cells that respond to physiological loading by increasing extracellular matrix (ECM) synthesis and incorporation [17-19]. In contrast, excessive loading is related to decreased matrix synthesis and increases in the production of proteolytic collagenases and aggrecanases, causing cartilage destruction [20-23]. Studies in tissue models that have examined the effects of cyclic compressive loading have generally applied a single loading protocol, lasting several hours to days of duration [18-20,24]. The biosynthetic matrix response has, however, been demonstrated to be augmented when a physiological compression operation is performed repeatedly over several days $[18,19,24]$. Repeated loading protocols are more characteristic of loading in vivo, in which periods of cyclic loading rarely last more than $1 \mathrm{~h}$ and are not only interspersed with periods of partial recovery but also periods of full recovery that last at least $16 \mathrm{~h}$ per day [25]. Accordingly, healthy articular cartilage depends on intermittent physiological loading, in which cycles of cartilage loading and unloading maintain homeostasis [26]. Despite the importance of intermittent loading, it is rarely considered in experimental cartilage models. From a preclinical perspective, this potentially limits their translational potential, as the influence of intermittent loading may modulate the chondrocyte response to treatments.

Insulin-like growth factor-1 (IGF-1) and transforming growth factor beta (TGF- $\beta$ ) are important anabolic inducers in articular cartilage. IGF-1 is a $7.5 \mathrm{kDa}$ polypeptide produced by the liver that reaches the articular cartilage through the synovial fluid [27] but is also secreted locally by chondrocytes [28]. Exogenous addition of IGF-1 to monolayer- or explant cultures promotes synthesis of proteoglycans and attenuates their degradation [29-31]. IGF-1 also counteracts the effects of catabolic agents, by enhancing the recovery of proteoglycans after their depletion [32,33]. IGF-1 is important for type II collagen synthesis and matrix incorporation [31,34-36]. Previous studies have shown that IGF-1 and dynamic compression increase cartilage formation in an additive manner by matrix incorporation of radiolabeled proline and sulphate, suggesting that compression and IGF- 1 act through different cellular pathways $[35,36]$. TGF- $\beta$ exists in three isoforms, namely TGF- $\beta 1$, TGF- $\beta 2$ and TGF- $\beta 3$, which are all secreted by chondrocytes. The need for TGF- $\beta$-induced Smad $2 / 3$ signaling in preserving cartilage homeostasis through blocking of hypertrophic maturation is well documented [37-41]. Mechanical loading was previously suggested to induce TGF$\beta$ signaling, as upregulation of $S \operatorname{mad} 2 / 3$ response genes was reported in cartilage explants following physiological and excessive dynamic compression [42]. The transduction of homeostatic Smad2/ 3 signaling depends on ALK5, a TGF- $\beta$ type I receptor [43]. TGF- $\beta$ enhances the synthesis of proteoglycans [32,44-46] and type II collagen [45-47] and promotes the production of pericellular matrix (PCM) components, including fibronectin [48]. Fibronectin is abundantly present in the cartilage PCM and binds the chondrocyte through membrane-spanning integrins [49]. Fibronectin has been suggested to be involved in sequestering the latent TGF- $\beta$ complex in the cartilage matrix [50].

This study aimed to develop an ex vivo cartilage model that can be used to characterize the matrix turnover effects of long-term intermittent dynamic compression. Bovine cartilage explants were cultured for three weeks, and low-grade dynamic compression was performed five times weekly. We examined the effects on the cartilage matrix by biomarker measurements of type II collagen formation (PRO-C2) and fibronectin turnover (FBN-C) in the conditioned media from explants. We further investigated how long-term intermittent dynamic compression modulated the matrix in response to IGF-1 and TGF- $\beta 1$.

\section{Materials and Methods}

\subsection{Bovine Articular Cartilage Explant Cultures}

Full-depth bovine cartilage explants were isolated from the lateral and medial femoral condyles of calf stifle joints (age below 2 years, any gender), obtained from the local abattoir 
(Harald Hansen Eftf., Slangerup, Denmark) within 24 h post-mortem. Explants were isolated by pushing a $3 \mathrm{~mm}$ biopsy punch (Scandidact, Odder, Denmark) through the cartilage and running a scalpel along the femoral bone, releasing the tissue. Explants were randomly assigned to sterile 24-well culture plates and washed two times with 1:1 Dulbecco's Modified Eagle Medium: Nutrient Mixture F-12 with GlutaMAXTM (DMEM/F12-GlutaMAX ${ }^{\mathrm{TM}}$ ) (Invitrogen, MA, USA) supplemented with $1 \%{ }^{\mathrm{TM}}$ supplemented with $\mathrm{P} / \mathrm{S}$ is referred to as "culture medium". Explants were subsequently incubated for $30 \mathrm{~min}$ at standard culture conditions $\left(37^{\circ} \mathrm{C}, 5 \% \mathrm{CO}_{2}\right.$, and $95 \%$ humidity) in culture medium supplemented with $2.5 \mu \mathrm{g} / \mathrm{mL}$ Fungizone ${ }^{\circledR}$ (Amphotericin B, Sigma-Aldrich) to prevent fungal contamination. Explants were equilibrated in the culture medium overnight. The next day was defined as day 0 of the culture. The 24-well culture plates contained in each well a $15.5 \mathrm{~mm}$ (outer diameter), $5 \mathrm{~mm}$ (inner diameter) and $0.5 \mathrm{~mm}$ (height) sterile polycarbonate washer ( $\mathrm{RH}$ Nuttall Ltd., Burmingham, UK) that helped position explants centrally in wells for mechanical compression procedures, while still allowing unconfined loading of the explants. The washers were included in the cultures for the entire duration of studies. The culturing lasted for 21 days.

\subsection{Assessment of Explant Metabolic Activity}

The explant metabolic activity was determined at day 0 and every seven days with the Alamar Blue (resazurin) metabolic assay [51] (Invitrogen). Explants were incubated for $3 \mathrm{~h}$ in 10\% Alamar Blue in the culture medium. The explant Alamar Blue medium was transferred to a black 96-well polystyrene plate (Sigma-Aldrich) post incubation and fluorescence was measured at $540 \mathrm{~nm}$ excitation and $590 \mathrm{~nm}$ emission on a microtiter plate fluorimeter (SpectraMax M5, Molecular Devices, San Jose, CA, USA). The fluorescence from four wells without explants was used for background adjustment of all samples. Explants were washed two times in the culture medium followed by 30 min incubation in $2.5 \mathrm{\mu g} / \mathrm{mL}$ Fungizone ${ }^{\circledR}$ to wash out the blue staining of explants left by Alamar Blue.

\subsection{Dynamic Mechanical Compression Procedure}

Dynamic compressive loading of explants was carried out using the Electroforce $5500^{\circledR}$ test instrument (TA Instruments, Delaware, USA) with an accompanying 24-well plate compressive loading fixture system (TA Instruments; Figure 1). The Electroforce $5500^{\circledR}$ instrument is incubator-housed, which allows compressive loading to be performed at standard incubation conditions. The accessory 24 -well plate fixture system consists of a sterile chamber that permits equilibration with the incubator temperature and atmosphere, along with two loading platens. The bottom platen is linked to a chamber-integrated load sensor. The top platen has 24 retractable pins designed for fixating explants in their individual wells, while being linked to an overhead motor through a shaft, allowing for dynamic compression. For each compression run, the platens were mounted to the sterile chamber inside a laminar flow cabinet. A 24-well plate with explants was transferred to the bottom plate in the chamber and fixated under the top platen. The explant-loaded chamber was then connected to the Electroforce $5500^{\circledR}$ instrument. Unconfined compressive loading was applied to the explants in a sine wave at $1 \mathrm{~Hz}$ frequency for 1200 cycles $(20 \mathrm{~min})$, with a cycle peak load of $1 \mathrm{MPa}$ and valley load of $0.01 \mathrm{MPa}$. The settings for the loading procedure were programmed using the WinTest ${ }^{\circledR}$ Software (TA instruments). The loading applied was monitored in real time with the WinTest ${ }^{\circledR}$ Software. The loading platens were autoclaved at the end of each loading procedure. The compressive loading procedure was carried out five consecutive days each week, and at least $16 \mathrm{~h}$ passed between each stimulation protocol. 
A

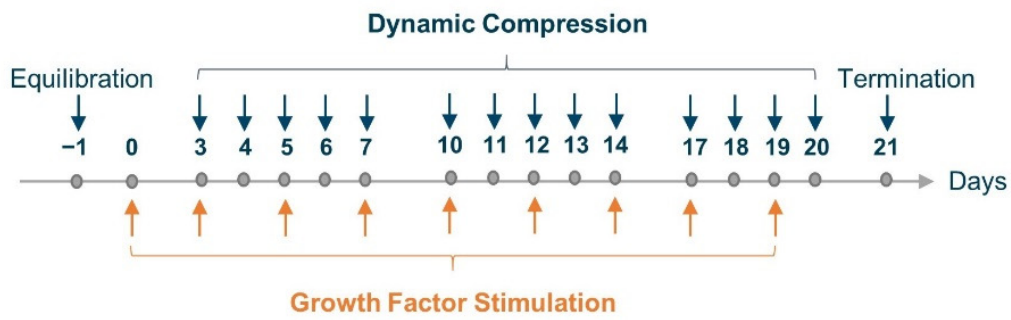

B

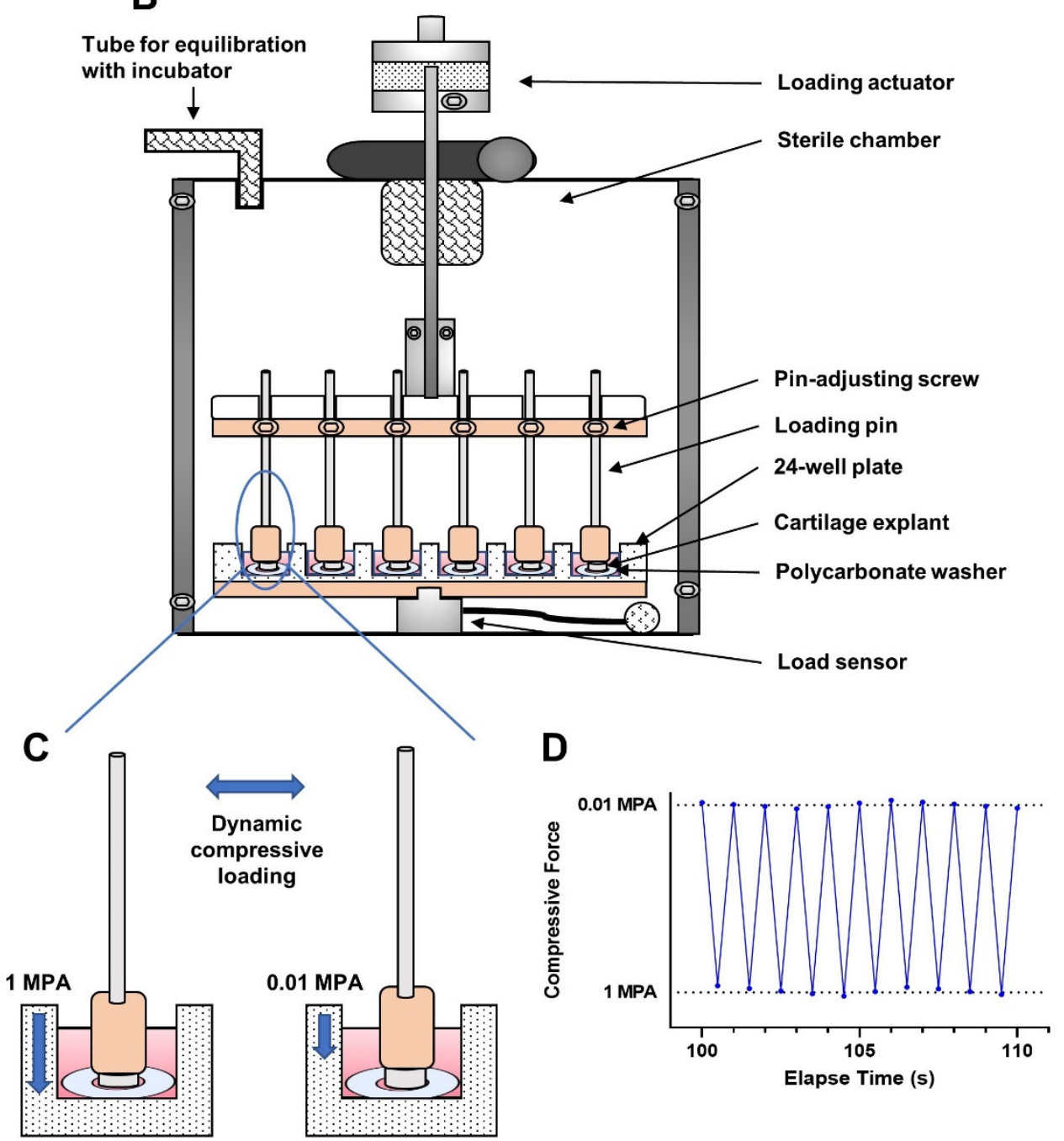

Figure 1. Dynamic compressive loading model. (A) Timeline of intermittent dynamic compression studies. (B) Compressive loading system. In a 24-well plate, loading pins fixate explants in individual wells by tightening pin-adjusting screws. Polycarbonate washers position explants centrally in wells, but do not confine them, allowing for unconfined compression. Compressive loading is applied simultaneously to all explants by a loading actuator. (C) Dynamic compressive loading of a single explant. During dynamic compression, the loading pin continuously fixates the explant. (D) Representative elapse time of $10 \mathrm{~s}$, corresponding to 10 loading cycles. Shown is the force logged every $0.5 \mathrm{~s}$ by the load sensor. The total loading procedure elapses 1200 cycles, corresponding to $20 \mathrm{~min}$. 


\subsection{Dynamic Compression Studies}

Bovine cartilage explants were treated with $100 \mathrm{ng} / \mathrm{mL}$ human recombinant IGF-1 (Sigma-Aldrich), $50 \mathrm{ng} / \mathrm{mL}$ human recombinant TGF- $\beta 1$ (R\&D Systems, Minneapolis, MN, USA) and/or $2 \mu \mathrm{M}$ SB525334 (Sigma-Aldrich). IGF-1 was reconstituted in sterile PBS, TGF- $\beta 1$ was reconstituted in $4 \mathrm{mM}$ hydrochloric acid $(\mathrm{HCl})$ containing $0.1 \%$ bovine serum albumin (BSA) and SB525334 was reconstituted in dimethyl sulfoxide (DMSO) before further dilution in culture medium. The DMSO volume was 1\% in the SB525334 working solution. Then, 24 technical replicate explants were assigned to each treatment: 12 dynamically compressed explants and 12 unloaded explants. Explants treated only with culture medium were included as vehicle control (w/o). Treatments were changed three times per week and added immediately prior to compressive loading procedures. Conditioned media was collected in 96 well microtiter plates upon media change and stored at $-20^{\circ} \mathrm{C}$ for biomarker analysis.

\subsection{Biomarker Assays}

Enzyme-linked immunosorbent assays (ELISA) were used to measure biomarker levels in conditioned media from the explants. PRO-C2 is a competitive ELISA that measures the N-terminal pro-peptide of type IIB procollagen, named PIIBNP. The Nterminal pro-peptide of type II procollagen (PIINP) exists in two splice variants, IIA and $\mathrm{IIB}$, due to alternative splicing of transcripts from the type II procollagen gene (COL2A1). Mature chondrocytes produce mainly IIB transcripts [52]. The PIIBNP pro-peptide is cleaved from type IIB alpha chains during tropocollagen triple helix formation, thus being a biomarker of type IIB collagen formation $[53,54]$. FBN-C is a direct ELISA that measures fibronectin fragments containing the unique C-terminal sequence VQADREDSRE [55].

Biomarker concentrations in explant conditioned media were quantified at baseline (day 0 ) and every seven days. Briefly outlined, streptavidin-coated 96-well plates were coated for $30 \mathrm{~min}$ at $20^{\circ} \mathrm{C}$ with biotin-labeled biomarker-antigen peptides. Unbound peptide was eliminated by washing. $20 \mu \mathrm{L}$ standards, samples and inter-assay controls were added followed by addition of $100 \mu \mathrm{L} /$ well horseradish peroxidase-labeled (FBN-C) or unlabeled (PRO-C2) mouse monoclonal antibody in an assay-specific buffer. Plates were incubated overnight at $4{ }^{\circ} \mathrm{C}$ (FBN-C) or for $2 \mathrm{~h}$ at $20^{\circ} \mathrm{C}$ (PRO-C2) with the primary antibody. Following washing, PRO-C2 was incubated for $1 \mathrm{~h}$ with a secondary anti-mouse horseradish peroxidase (HRP)-labeled antibody. The plates were washed and the HRPsubstrate 3,3',5,5'-tetramethylbenzidine was added to initiate a color reaction that was terminated after $15 \mathrm{~min}$ by addition of $0.1 \mathrm{M}$ sulfuric acid. Absorbance with optical density readout was measured at $450 \mathrm{~nm}$ excitation and $650 \mathrm{~nm}$ emission on a microtiter plate reader (SpectraMax ${ }^{\circledR}$ M3, Molecular Devices). Standard curves were plotted using a four-parametric mathematical fit.

\subsection{Statistical Analysis}

For biomarker measurements, any values below the lower limit of measurement range (LLMR) were imputed as LLMR. For both PRO-C2 and FBN-C, the lower limit of the measurement range was defined as the lower limit of detection, equal to three standard deviations of a blank sample.

All longitudinal data for alamarBlue ${ }^{\circledR}$, PRO-C2 and FBN-C were transformed to a natural logarithm scale to achieve variance homogeneity between distinct time points of culture and between experiments. The transformed data was then analyzed using linear mixed models, with day of culture, compression, treatment and baseline values (day 0) of the biomarker as covariates. The models assumed interaction between treatment (vehicle, growth factor or antagonist), compression and day of culture. Explant replicate was included as a random effect, thereby specifying an exchangeable correlation structure. Least square mean estimates were back-transformed to geometric means. For the respective biomarker outcomes, only the estimated compression contrast between treatment groups was reported. The contrasts were reported as the ratios between geometric means, and 
$p$-values were adjusted for multiplicity with Tukey's or Sidak's method to target a significance level of $5 \%$. The analysis was carried out with $\mathrm{R}$ version 3.6.3 (R Foundation for Statistical Computing, Vienna, Austria) and RStudio version 1.4.1106 (RStudio, PBC, Boston, MA, USA) using the packages "tidyverse," "emmeans," "lme4" and "lmerTest" [56-59]. Graphical illustrations were made with GraphPad Prism version 9.0 (GraphPad Software, San Diego, CA, USA).

\section{Results}

\subsection{Long-Term Intermittent Compression Induces Cartilage Formation}

Bovine cartilage explants were cultured for three weeks and subjected to dynamic compression five times per week (Figure 1A). Compression conditions applied to each explant consisted of a sine wave at $1 \mathrm{~Hz}$ frequency running for 1200 cycles (20 min); compression cycles had a peak compressive force of $1 \mathrm{MPa}$ and valley load of $0.01 \mathrm{MPa}$ (Figure 1B-D).

Application of dynamic compression five times weekly was compared to application three times weekly in culture media alone. We observed no effect of compression on metabolic activity - a surrogate for cell viability—at either three or five weekly procedures compared to unloaded samples (Figure 2A,B). Compression three and five times per week increased PRO-C2 levels compared to non-compressed naïve explants (Figure 2C). At the day 21 endpoint, a 3.6-fold PRO-C2 increase was measured in explants with three weekly compression procedures $(p=0.027)$, while five weekly procedures resulted in a 5.5-fold PRO-C2 increase compared to unloaded explants $(p=0.0001)$ (Figure 2C,D). The initial peak in PRO-C2 release observed on day 0 is always observed in the bovine ex vivo model and is thought to be a reaction to the tissue extraction [60]. Compression three or five times per week increased FBN-C release compared to naïve unloaded samples (Figure 2E). On day 21 of culture, FBN-C was increased 4.3-fold by three times compression $(p<0.0001)$ and 3.7-fold by five times compression $(p<0.0001)$, compared to unloaded explants (Figure 2E,F).

\subsection{Long-Term Intermittent Compression Acts Synergistically with IGF-1}

We investigated the effect of long-term intermittent compression in explants treated with IGF-1. Explants were subjected to dynamic compression five times weekly. Naïve explants were co-cultured as a control for the ability of compression to induce cartilage formation alone. Compression did not alter the metabolic activity in naïve explants, or those treated with $100 \mathrm{ng} / \mathrm{mL}$ IGF-1 (Figure 3A,B). Compression of naïve explants increased PRO-C2 compared to unloaded naïve explants (Figure 3C). On day 21, PRO-C2 was 2.9-fold higher in compressed naïve explants compared to unloaded naïve explants $(p<0.0001)$ (Figure 3C,D). A significant separation between compressed IGF-1 treated explants versus unloaded IGF-1 explants was observed on day 21, where PRO-C2 was elevated 1.6-fold $(p=0.0215)$ (Figure 3C,D). On day 21, the absolute difference in PRO-C2 levels in compressed IGF-1 versus unloaded IGF-1 explants was $89 \mathrm{ng} / \mathrm{mL}$; and $26 \mathrm{ng} / \mathrm{mL}$ in compressed naïve versus unloaded naïve explants. Thus, the compression-induced increase in PRO-C2 was 3.3-fold greater in IGF-1-treated explants than in naïve explants, demonstrating a synergistic interaction (Figure 3D). 
A

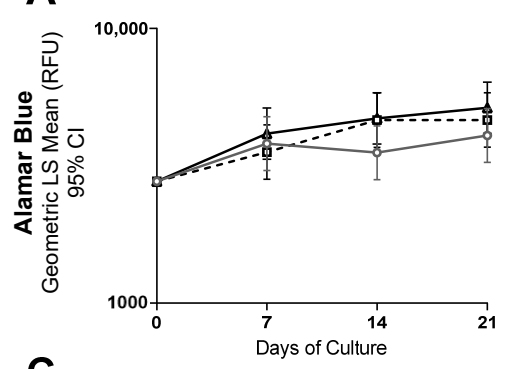

C

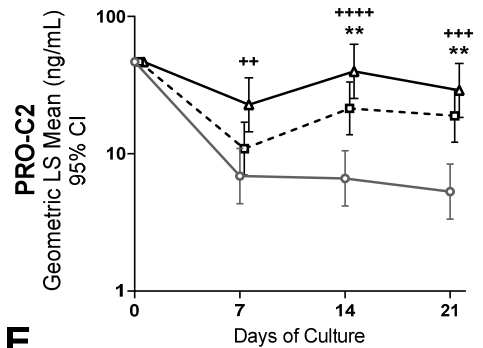

E

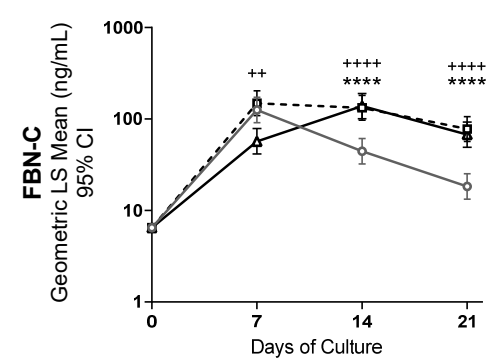

B

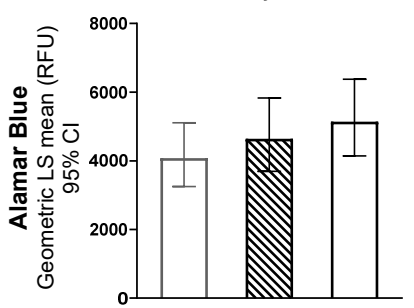

- $-6 / 0$

$\rightarrow \mathrm{w} / 0+3 x$ compression

$\triangle$ w/o $+5 x$ compression

* $=w / 0+3 x$ compression vs. $w / 0$

$+=w / 0+5 x$ compression vs. $w / 0$
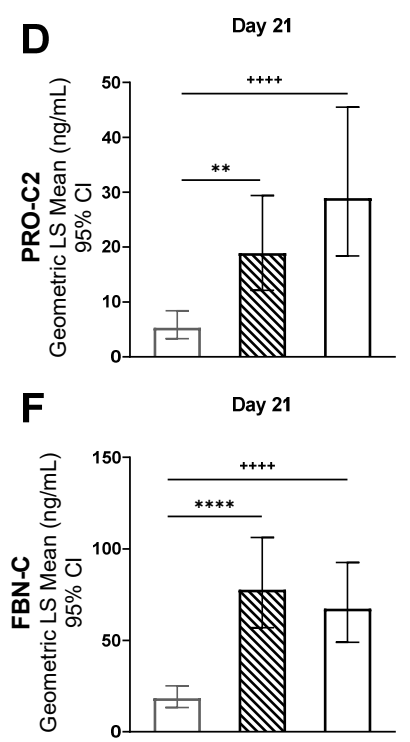

Figure 2. Dynamic compression induces cartilage remodeling. Cartilage ECM turnover biomarkers released to explant conditioned media over a three-week culture period. Bovine cartilage explants ( $n=6$ for each condition) were cultured in culture media alone (w/o), dynamically compressed 3 times per week (w/o $+3 \times$ compression) or 5 times per week (w/o + 5× compression). (A) Alamar Blue metabolic activity assessment of explants at day 0, 7, 14 and 21 of culture. (B) Metabolic activity at day 21. (C) PRO-C2 release from explants into conditioned media measured at day 0,7, 14 and 21 of culture. (D) PRO-C2 release at day 21. (E) FBN-C release into conditioned media at day 0, 7, 14 and 21 of culture. (F) FBN-C measured at day 21. Data point and bars represent geometric least-squares (LS) mean values and error bars represent $95 \%$ confidence levels. $(\mathbf{A}, \mathbf{C}, \mathbf{E})$ are presented on a logarithmic scale and $(\mathbf{B}, \mathbf{D}, \mathbf{F})$ are presented on a linear scale. Asterisks $\left({ }^{*}\right.$ or + ) indicate Tukey-adjusted $p$-values: ${ }^{*} /+: p<0.05,{ }^{* *} /++: p<0.01,{ }^{* * *} /+++: p<0.001,{ }^{* * * *} /++++: p<0.0001$. $* * * *++++: p<0.0001$.

Long-term intermittent compression resulted in significant FBN-C increases on day 21 of culture. Compression of naïve explants increased FBN-C by 3.1-fold versus unloaded naïve explants $(p<0.0001)$; and similarly, FBN-C was increased 2.5 -fold in compressed IGF-1 versus unloaded IGF-1 explants ( $p=0.0006)$. However, IGF-1 did not elevate FBN-C levels compared to culture media alone (Figure 3E,F).

\subsection{The Anabolic Effect of High-Dose TGF- $\beta 1$ Is Not Affected by Compressive Load}

We examined the effects of compressive loading in the presence of $50 \mathrm{ng} / \mathrm{mL}$ exogenous TGF- $\beta 1$. Long-term intermittent compression of naïve or TGF- $\beta 1$-treated explants did not affect the metabolic activity (Figure 4A,B). Dynamic compression of naïve explants elevated PRO-C2 compared to naïve unloaded explants on day $14(p=0.0029)$ and day $21(p=0.0009)$. Compression of TGF- $\beta 1$-stimulated explants did not significantly increase PRO-C2 compared to TGF- $\beta 1$ alone at any time point (Figure $4 \mathrm{C}, \mathrm{D}$ ). As observed previously, compression of naïve explants led to increased FBN-C release to the conditioned medium compared to unloaded naïve explants on day $14(p=0.0006)$ and day $21(p=0.0007)$ 
(Figure 4E). Compression did not affect FBN-C release in explants treated with TGF- $\beta 1$; however, TGF- $\beta 1$ treatment increased FBN-C release (Figure 4E,F).
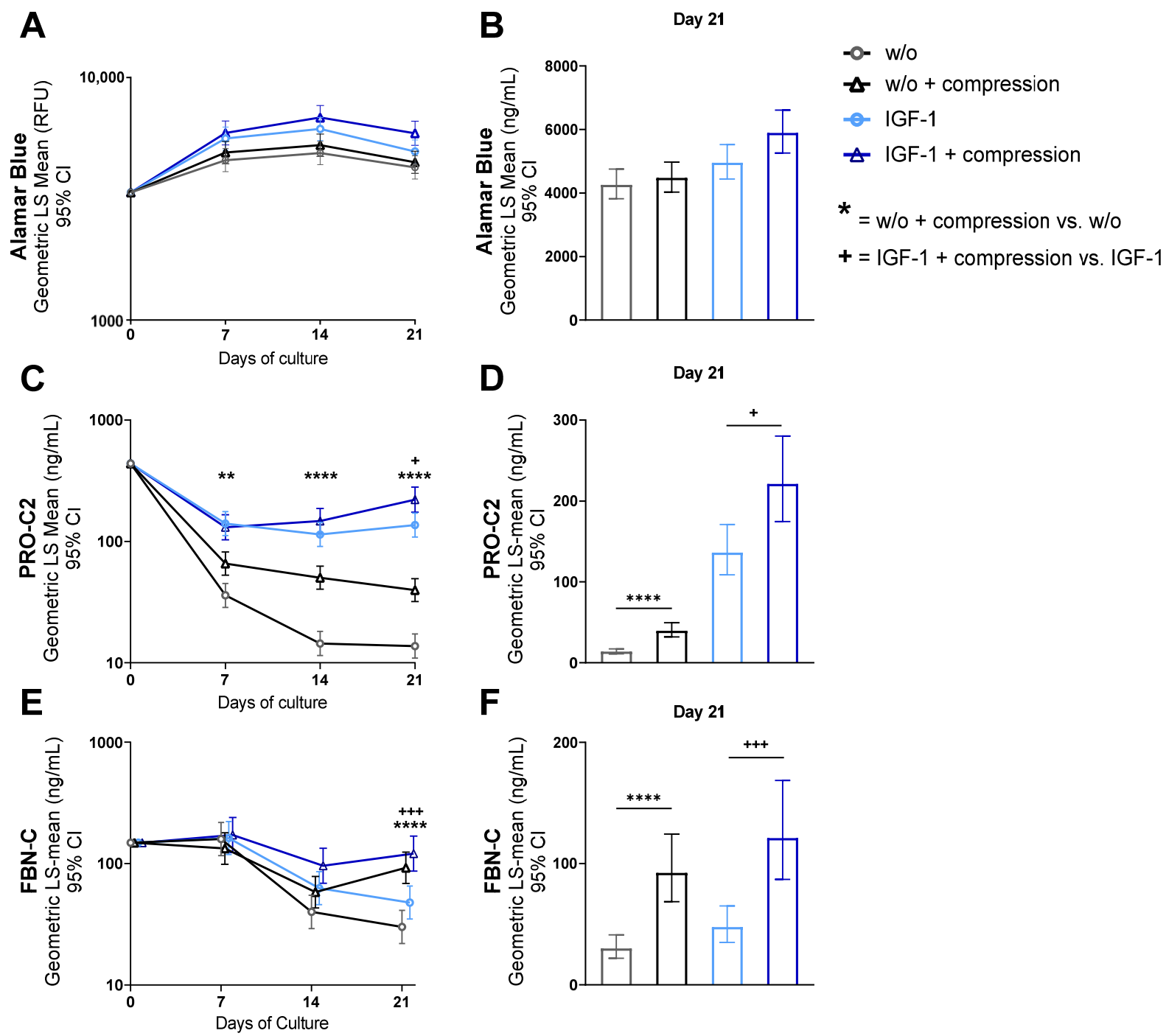

Figure 3. Effect of dynamic compression on IGF-1-induced cartilage remodeling. Cartilage ECM turnover biomarkers released to explant conditioned media over a three-week culture period. Bovine cartilage explants $(n=12$ for each condition) were cultured in IGF-1 [100 ng/mL] in the absence of loading (IGF-1) or with 5 times weekly compression (IGF-1 + compression). Explants cultured in culture media without (w/o) or including compression (w/o + compression) were co-cultured. (A) Alamar Blue metabolic activity assessment of explants at day 0, 7, 14 and 21 of culture. (B) Metabolic activity at day 21. (C) PRO-C2 release from explants into conditioned media measured at day 0, 7, 14 and 21 of culture. (D) PRO-C2 release at day 21. (E) FBN-C release into conditioned media at day 0, 7, 14 and 21 of culture. (F) FBN-C measured at day 21. Data point and bars represent geometric least-squares (LS) mean values and error bars represent $95 \%$ confidence levels. (A,C,E) are presented on a logarithmic scale and $(\mathbf{B}, \mathbf{D}, \mathbf{F})$ are presented on a linear scale. Asterisks $\left({ }^{*}\right.$ or +$)$ indicate Tukey-adjusted $p$-values: ${ }^{*} /+: p<0.05,{ }^{* *} /++: p<0.01,{ }^{* * *} /+++: p<0.001$.

\subsection{Inhibition of the TGF- $\beta$ Type I Receptor ALK5 Blocks Cartilage Remodeling}

Given the lack of compression effect in TGF- $\beta 1$-treated explants, we investigated whether the ALK5-inhibitor, SB-525334, could inhibit compression-induced cartilage turnover. Treatment with $2 \mu$ M SB-525334 strongly inhibited the metabolic activity in compressed naïve explants (SB-525334 + compression vs. w/o + compression) and explants treated with $50 \mathrm{ng} / \mathrm{mL}$ TGF- $\beta 1$ (SB-525334 + TGF- $\beta 1$ vs. TGF- $\beta 1$ ) at day 14 and 21 of culture (all $p<0.0001$ ). Explants were, however, still viable (Figure 5A,B). PRO-C2 was increased by compression in naïve ex- 
plants, compared to naïve unloaded explants on day 21 ( $p=0.0106$ ) (Figure 5C,D). SB-525334 inhibited the release of PRO-C2 in compressed naïve explants and TGF- $\beta 1$-stimulated explants, compared to the untreated counterparts (all $p<0.0001$ at day 7, 14 and 21) (Figure 5C,D). PRO-C2 release was below the lower limit of detection with SB-525334 treatment in most explants on day 14, indicating that type II collagen formation was blocked from day 14 and onward culture by accumulation of the inhibitor. SB-525334 treatment strongly inhibited FBN-C release in compressed naïve- and TGF-B1-treated explants, compared to their unloaded counterparts (all $p<0.0001$ at day 7, 14 and 21). As for PRO-C2, FBN-C release with SB-525334 treatment was below the lower limit of detection in most explants on day 14, indicating a blockade in FBN-C turnover (Figure 5E,F).
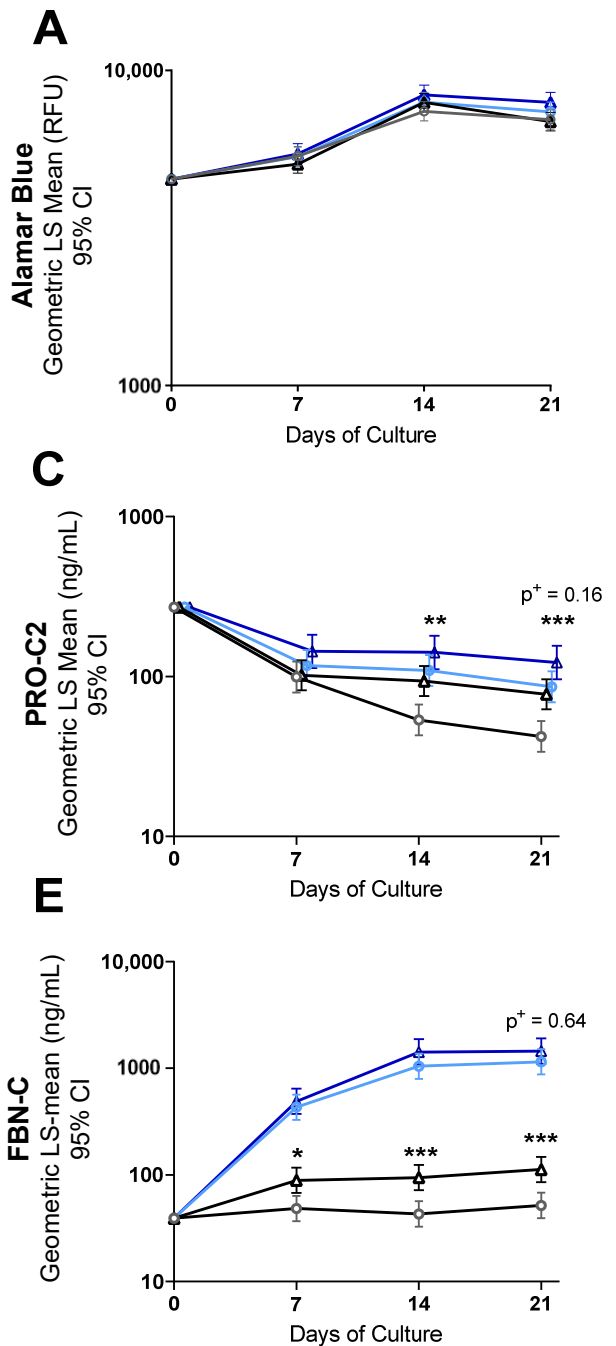

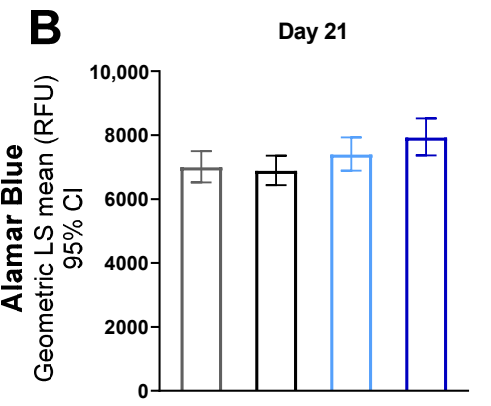

- $w / 0$

- w/o + compression

- 0 - TGF- $\beta 1$

$\triangle$ TGF- $\beta 1+$ compression

* $=$ w/o + compression vs. w/o

$+=$ TGF $-\beta 1+$ compression vs. TGF- $\beta 1$
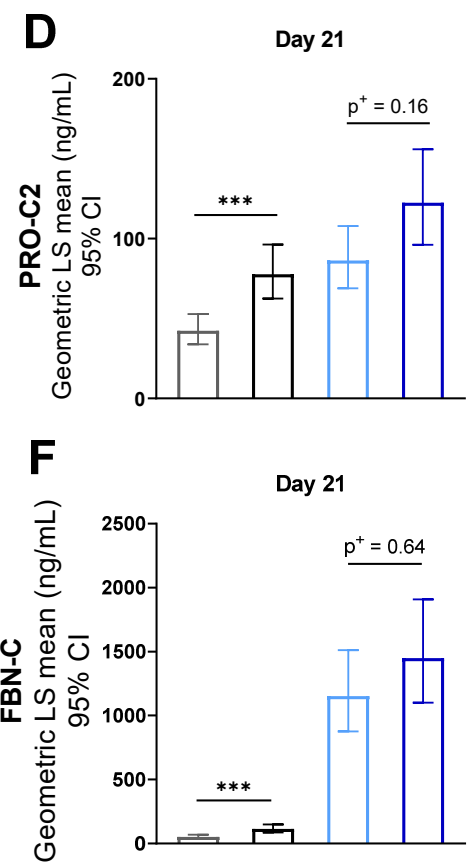

Figure 4. Effect of dynamic compression on TGF- $\beta 1$-induced cartilage remodeling. Cartilage ECM turnover biomarkers released to the explant conditioned media over a three-week culture period. Bovine cartilage explants $(n=12$ for each condition) were cultured in TGF $\beta-1[50 \mathrm{ng} / \mathrm{mL}]$ in the absence of loading (TGF $\beta-1$ ) or with 5 times weekly compression (TGF $\beta-1+$ compression). (A) Alamar Blue metabolic activity assessment of explants at day 0, 7, 14 and 21 of culture. (B) Metabolic activity at day 21. (C) PRO-C2 release measured at day 0, 7, 14 and 21 of culture. (D) PRO-C2 release at day 21. (E) FBN-C release measured at day 0, 7, 14 and 21 of culture. (F) FBN-C measured at day 21. Data point and bars represent geometric least-squares (LS) mean values and error bars represent $95 \%$ confidence levels. (A,C,E) are presented on a logarithmic scale and $(\mathbf{B}, \mathbf{D}, \mathbf{F})$ are presented on a linear scale. Asterisks $\left({ }^{*}\right.$ or +$)$ indicate Tukey-adjusted $p$-values: $* /+: p<0.05, * * /++: p<0.01, * * * /+++: p<0.001,{ }^{* * * *} /++++: p<0.0001$. 

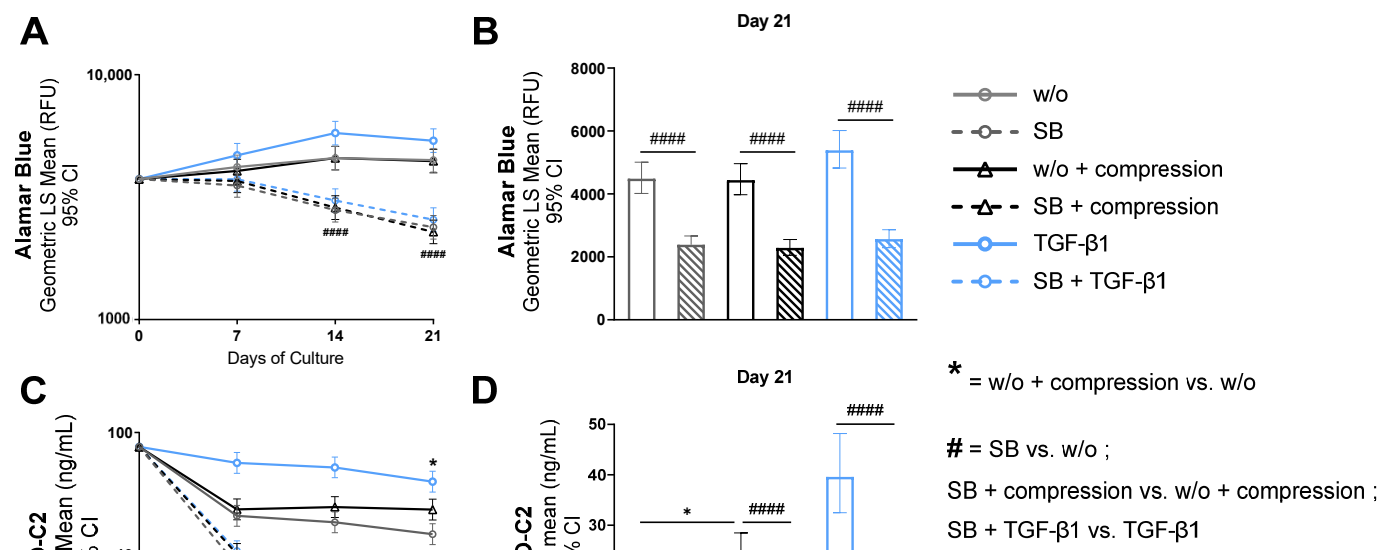

* $=$ w/o + compression vs. w/o

\# = SB vs. w/o ;

$\mathrm{SB}+$ compression vs. $\mathrm{w} / \mathrm{o}+$ compression ;

$\mathrm{SB}+$ TGF- $\beta 1$ vs. TGF- $\beta 1$

D
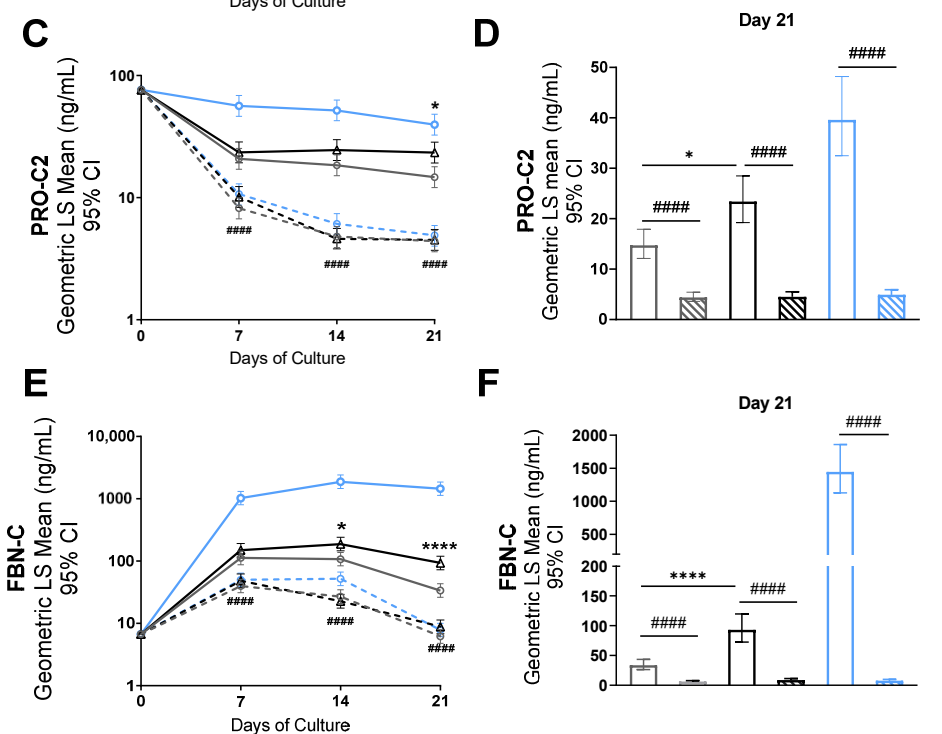

F

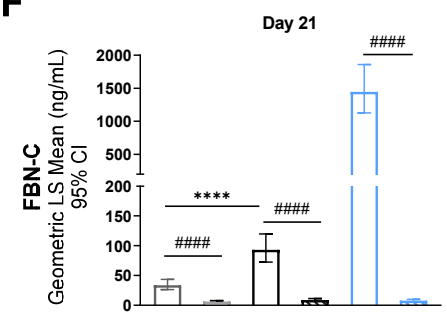

Figure 5. Inhibition of ALK5 blocks cartilage remodeling induced by compressive loading. Cartilage ECM turnover biomarkers released to the explant conditioned media over a three-week culture period. Bovine cartilage explants $(n=12$ for each condition) were treated with SB-525334 without loading (SB) or compressed 5 times per week in the absence( $w / o+$ compression) or presence of SB-525334 (SB + compression). Explants cultured in TGF $\beta-1$ [50 ng/mL] in the absence(TGF $\beta-1)$ or presence of SB-525334 (SB + TGF $\beta-1$ ) were co-cultured as a control of the SB-525334 ability to block signaling from the ALK5 receptor. (A) alamarBlue metabolic activity assessment at day 0, 7, 14 and 21 of culture. (B) Metabolic activity at day 21 endpoint. (C) PRO-C2 release measured at day 0, 7, 14 and 21 of culture. (D) PRO-C2 release at day 21. (E) FBN-C release measured at day 0, 7, 14 and 21 of culture. (F) FBN-C measured at day 21. Data points and bars represent geometric least-squares (LS) mean values and error bars represent $95 \%$ confidence intervals. (A,C,E) are presented on a logarithmic scale and $(\mathbf{B}, \mathbf{D}, \mathbf{F})$ are presented on a linear scale. Asterisks $\left({ }^{*}\right.$ or \#) indicate Sidak-adjusted $p$-values of the shown contrasts: * /\#: $p<0.05,{ }^{* *} / \# \#: p<0.01, * * *$ \#\#\#: $p<0.001, * * * * \# \# \#: p<0.0001$.

\section{Discussion}

This study aimed to characterize the matrix turnover effects of long-term intermittent dynamic compression in a novel ex vivo cartilage model. We showed that daily low-grade cyclic compression of cartilage explants leads to increased type II collagen formation and pericellular remodeling, which can be distinguished by the biomarker release of PRO-C2 and FBN-C to the conditioned media. We demonstrated that PRO-C2 release was greater when dynamic compression was repeated five versus three times per week, while FBN-C release was similar at three or five operations. Thus, we showed that type II collagen formation was augmented with repeated loading operations, in agreement with previous studies that studied the effect of repeated loading on type II collagen mRNA [18,24]. We further found that PRO-C2 increased synergistically as a result of combining IGF-1 and intermittent dynamic compression. Our finding is similar to a previous study in which IGF-1 and dynamic compression increased collagen formation in an additive manner during $0.1 \mathrm{~Hz}$ stimulation for $48 \mathrm{~h}$ [36]. TGF- $\beta 1$ increased both PRO-C2 and FBN-C release; however, either increase was not affected by intermittent dynamic compression. Instead, we found that compression-induced cartilage formation was dependent on TGF- $\beta$ signaling, 
as PRO-C2 and FBN-C release from dynamically compressed explants was blocked by the ALK5 inhibitor SB-525334. The SB-525334 inhibitor was previously shown to inhibit aggrecan and type II collagen mRNA levels in TGF- $\beta 1$-stimulated rat chondrocytes [45].

Our focus was on intermittent dynamic compression, in which each stimulation procedure lasted for only $20 \mathrm{~min}$. This is a relatively short time duration, in contrast to most other studies investigating the effects of cyclic cartilage compression. The time of the loading procedure was generally longer in other studies, spanning from 4 to $48 \mathrm{~h}$, or even weeks of continuous loading $[18-20,24,36]$. However, we wanted to simulate in vivo conditions, in which periods of cyclic loading rarely last more than $1 \mathrm{~h}$ and are interspersed with periods of partial recovery but also of full recovery that last at least $16 \mathrm{~h}$ per day [25]. We only applied a single stimulation protocol per day. It is possible that a greater effect of intermittent compression would be achieved by having multiple 20 min stimulations per day, allowing time for recovery in between, or by prolonging the daily stimulation protocol past $20 \mathrm{~min}$. These will be considerations for future studies.

Normal joint motion in vivo produces a superposition of compressive, tensile and shear deformations of cartilage. It is worth noting that different types of mechanical stress are shown to confer different effects in cartilage tissue. While moderate compressive loading has generally been shown to induce anabolic effects, shear stress has been associated with catabolic changes, including upregulation of pro-inflammatory proteases [61]. We used unconfined dynamic compression in this model, which mainly produces compressive stress in the axial direction as well as tensile stress in the radial direction [62]. We decided on unconfined compression, as confinement would not produce tensile stress in the radial direction, thus being less characteristic of in situ contact deformation [63]. The repeated stimulation protocol was $20 \mathrm{~min}$ of unconfined compression at $1 \mathrm{~Hz}$ frequency with peak cycle load of $1 \mathrm{MPa}$. We aimed to simulate physiological compressive loading similar to that exerted on cartilage during low-grade everyday exercise, such as when walking. The applied load was chosen based on literature review. Applied loads of 1000-1500 Newton (N) used to simulate walking in intact human tibiofemoral joints cause contact stress of articular cartilage ranging from 1-4 MPa [64]. Another study described that applied loads at $445-1779 \mathrm{~N}$ in intact knee joints produce a contact stress of $0.35-2.75 \mathrm{MPa}$, with increased compressive force corresponding to increased load distribution across the tibiofemoral surface [65]. Thus, the force used in this study is comparable to low-grade physiological load. However, we used bovine cartilage and it is possible that physiological contact stresses in bovine knee joints differ from human joints. Nonetheless, much of the information available on the chondrocyte responses to mechanical stimuli has been achieved in bovine explant cultures, as they provide a more controlled biomechanical environment than in vivo models [26]. In bovine cartilage explants, dynamic compressive stresses at 0.1-5 MPa and $0.1-1 \mathrm{~Hz}$ frequency generally produce biosynthetic responses $[36,66,67]$, while explants subjected to compressive forces of 6-10 MPa respond with increased apoptosis [21].

While it is unclear which underlying mechanisms resulted in the interaction between compression and IGF-1, it has been suggested that dynamic compression produces a radial fluid flow that aids the distribution of growth factors in the cartilage and, thus, may augment the stimulation of the embedded chondrocytes [68]. Indeed, Bonassar et al. found that dynamic compression accelerated the transport of iodine-labeled IGF-1 into the cartilage matrix [36]. On a cellular level, mechanotransduction appears to depend on gated ion channels such as PIEZO and TRPV4 [69], cytoskeletal changes such as mechanical activation of the primary cilia [70] as well as direct receptor-stimulation by cytokines and growth factors secreted in response to loading. However, many of the processes involved in the mechanosensitivity of cartilage also depend on the interaction of the chondrocytes and the surrounding matrix, including integrin-mediated signaling. Jablonski et al. showed that integrin $\alpha 1 \beta 1$ responds to the osmotic pressure that is generated by mechanical loading [71]. Furthermore, mechanical forces may stimulate the release of growth factors bound in the matrix, such as IGF-1, which is stored inactivated in complex with IGF-binding proteins [72]. 
We did not find any significant contrasts between explants treated with compression and TGF- $\beta 1$, versus unloaded explants treated only with TGF- $\beta 1$. Instead, we demonstrated that TGF- $\beta$ signaling is important in relaying compression-induced cartilage remodeling, as ALK5 inhibition blocked the release of PRO-C2 and FBN-C from compressed explants. Hence, we speculate that the compression-induced PRO-C2- and FBN-C increase may in part be explained by activation of TGF- $\beta$ stored in the explant ECM. Cartilage ECM contains large stores of TGF- $\beta$, up to $300 \mathrm{ng} / \mathrm{mL}$ [73]. TGF- $\beta$ is secreted by chondrocytes in a latent form that associates with pericellular matrix proteins such as fibrillin, proteoglycans and fibronectin [74]. Latency-associated protein (LAP), part of the inactive TGF- $\beta$ complex, interacts directly with $\alpha \mathrm{v}$-integrins [74]. Integrins contribute to the activation of latent TGF- $\beta$ by two proposed mechanisms: (1) a protease-dependent mechanism, in which $\alpha \mathrm{V}$-integrins bind to the latent TGF- $\beta$ complex and proteinases simultaneously, facilitating enzymatic cleavage and TGF- $\beta$ release; (2) a protease-independent mechanism, in which integrins change the conformation of latent TGF- $\beta$ by transmitting cell traction forces [50]. The latter mechanism requires the association of the latent complex with mechanically resistant ECM. Proof of mechanically driven TGF- $\beta$ activation by contractile forces on the bond between LAP and $\alpha \mathrm{V}$-integrins has recently been demonstrated to occur in mechanically stressed cartilage [75]. Zhen et al. demonstrated that mechanical stress leads to a talin-centered cytoskeletal reorganization in chondrocytes, causing a stiffening that transmits to $\alpha \mathrm{v}$ integrins in the release of TGF- $\beta$ [75]. Madej et al. similarly demonstrated that both physiological and excessive compression of explants activates Smad2/3 signaling, linking compressive loading with TGF- $\beta$ activation [42]. Fibronectin is a mechanosensitive protein that becomes unfolded upon cell traction, and it has been suggested that ECM protein unfolding may reveal specific-integrin binding sites [50]. Fibronectin-knockout fibroblasts have been reported to poorly incorporate latent TGF- $\beta$ into their ECM and exhibit deficient mechanical activation by the $\alpha v \beta 6$-integrin [76]. In addition, fibroblasts with knockout of the $\alpha 5 \beta 1$ integrin, an integrin that is not directly involved in TGF- $\beta 1$ activation but central for the assembly of fibronectin fibrils, are similarly incapable of activating latent TGF- $\beta 1$ by $\alpha v \beta 6$-integrin-mediated cell traction [76]. Thus, this suggests a dependency for fibronectin as an ECM scaffold in the mechanical activation of TGF- $\beta$. We found that fibronectin degradation was increased by intermittent dynamic compression, supporting a hypothesis of mechanical-driven TGF- $\beta$ release in these studies. The fact that TGF- $\beta$ signaling increases FBN-C could be indicative of a feedback loop, in which mechanically released TGF- $\beta$ restores its own latent ECM pool, requiring sequestration by fibronectin for later mechanical activations.

A recurring concept in cartilage biology is that TGF- $\beta$ activity must be maintained within an appropriate range for the maintenance of homeostasis and structural integrity [43]. The dysregulation of TGF- $\beta$ activity is detrimental to the chondrocyte metabolism and contributes to the OA pathogenesis. Zhen et al. demonstrated that subchondral bone sclerosis occurring during OA progression causes excessive regional stress in the overlying articular cartilage, altering the distribution of TGF- $\beta$ activity, being relatively elevated in high-stress regions and decreased in low-stress regions compared to healthy cartilage [75]. Furthermore, anterior-cruciate ligament transection (ACLT) mice with $\alpha \mathrm{V}$-integrin knockout were protected against cartilage damage, suggesting that abolishment of excessive TGF- $\beta$ activation in articular cartilage attenuates OA progression [75]. We acknowledge that the $50 \mathrm{ng} / \mathrm{mL}$ recombinant active TGF- $\beta 1$ concentration used in these studies can be considered excessive; however, we did not observe metabolic abnormalities using this dose, as determined by Alamar Blue.

It has been demonstrated that fibronectin fragments (FN-fs) promote pro-inflammatory pathways in chondrocytes, and that especially the amino-terminal FN-fs induces potent catabolic effects [77]. The FBN-C biomarker applied here specifically targets the C-terminal of fibronectin and has been shown to recognize both full-length and fragmented fibronectin [55]. Thus, it is unlikely that FBN-C recognizes the previously characterized FN-fs. The FBN-C assay has been demonstrated to increase in cartilage explants stimu- 
lated with TGF- $\beta$ or with a combination of the catabolic factors TNF- $\alpha$ and Oncostatin M, suggesting that the assay measures an increase in fibronectin turnover [55].

We quantified biomarkers in the conditioned media to assess matrix turnover in this study. Biomarkers have the advantage that they quantify changes made to the ECM on a structural level. Gene expression data of aggrecan, type II collagen and MMPs is a more common outcome in measuring changes to the ECM; however, it does not quantify the final change that takes place in the tissue. The relative ease of biomarker measurements in culture media provides high throughput, and the same biomarkers may be measured in other bodily fluids such as serum or plasma, making findings translatable to clinical settings.

A limitation of our study is that we did not assess aggrecan formation. Unfortunately, there is a lack of reliable biomarker assays for aggrecan formation. The incorporation of radiolabeled sulfate or glycosaminoglycan extraction is currently the only structural measure of aggrecan formation in experimental cartilage models. The sensitivity and reproducibility of these methods are, however, poor. The ability of cartilage to withstand compressive loading owes primarily to the swelling pressure generated by the proteoglycan network during compression [63], and thus, it would be important to shed light on these processes in future studies.

We showed that long-term intermittent dynamic compression modulates the cartilage tissue response to growth factor stimulation. This implicates that intermittent mechanical loading is an integral part of the physiological joint environment and should be taken into consideration in translational cartilage models. Furthermore, this work highlights the need to increase understanding of the effects of mechanical loading on cartilage, especially in combination with the many growth factors and pro-inflammatory cytokines thought to be involved in cartilage maintenance and OA pathogenesis. It could also be applicable in a sport and rehabilitation perspective, where it may provide insight into the structural changes of cartilage in response to exercise. Finally, the effects of mechanical loading on chondrocytes and ECM turnover may manifest when testing novel drug candidates in a clinical setting, altering their therapeutic potential for better or worse.

Author Contributions: Conceptualization, C.S.T., A.-C.B.-J. and A.E.; methodology, A.E. and C.S.T.; software, A.E. and P.F.; validation, A.E.; formal analysis, A.E., F.S.G. and P.F.; investigation, A.E., S.S.G. and F.S.G.; resources, C.S.T., A.-C.B.-J. and M.A.K.; data curation, A.E., S.S.G. and F.S.G.; writing-original draft preparation, F.S.G. and C.S.T.; writing-review and editing, A.E., S.S.G., F.S.G., C.S.T., A.-C.B.-J., P.F. and M.A.K.; visualization, F.S.G. and A.E.; supervision, C.S.T.; project administration, C.S.T.; funding acquisition, C.S.T. All authors have read and agreed to the published version of the manuscript.

Funding: A.E. received funding from the Danish Research Foundation, Herlev, Denmark (Grant number: KU2017).

Institutional Review Board Statement: Not applicable.

Informed Consent Statement: Not applicable.

Data Availability Statement: Not applicable.

Acknowledgments: Special thanks to Helene Hector for providing support in the cell laboratory and with biomarker measurements.

Conflicts of Interest: P.F., C.S.T., A.-C.B.-J. and M.A.K. are employed by Nordic Bioscience. C.S.T., A.-C.B.-J. and M.A.K. are shareholders of Nordic Bioscience. A.E., F.S.G. and S.S.G. have no conflicts of interest.

\section{References}

1. Loeser, R.F.; Goldring, S.R.; Scanzello, C.R.; Goldring, M.B. Osteoarthritis: A disease of the joint as an organ. Arthritis Rheum. 2012, 64, 1697-1707. [CrossRef]

2. Fox, A.J.S.; Bedi, A.; Rodeo, S.A. The Basic Science of Articular Cartilage: Structure, Composition, and Function. Sports Health 2009, 1, 461-468. [CrossRef] 
3. Quicke, J.; Foster, N.; Thomas, M.; Holden, M. Is long-term physical activity safe for older adults with knee pain?: A systematic review. Osteoarthr. Cartil. 2015, 23, 1445-1456. [CrossRef] [PubMed]

4. Juhl, C.; Christensen, R.; Roos, E.; Zhang, W.; Lund, H. Impact of Exercise Type and Dose on Pain and Disability in Knee Osteoarthritis: A Systematic Review and Meta-Regression Analysis of Randomized Controlled Trials. Arthritis Rheumatol. 2014, 66, 622-636. [CrossRef] [PubMed]

5. Roos, E.; Juhl, C. Osteoarthritis 2012 year in review: Rehabilitation and outcomes. Osteoarthr. Cartil. 2012, 20, 1477-1483. [CrossRef]

6. Amin, S.; Baker, K.; Niu, J.; Clancy, M.; Goggins, J.; Guermazi, A.; Grigoryan, M.; Hunter, D.J.; Felson, D. Quadriceps strength and the risk of cartilage loss and symptom progression in knee osteoarthritis. Arthritis Rheum. 2008, 60, 189-198. [CrossRef] [PubMed]

7. Otterness, I.G.; Eskra, J.D.; Bliven, M.L.; Shay, A.K.; Pelletier, J.P.; Milici, A.J. Exercise protects against articular cartilage degeneration in the hamster. Arthritis Rheumatol. 1998, 41, 2068-2076. [CrossRef]

8. Roos, E.; Dahlberg, L. Positive effects of moderate exercise on glycosaminoglycan content in knee cartilage: A four-month, randomized, controlled trial in patients at risk of osteoarthritis. Arthritis Rheum. 2005, 52, 3507-3514. [CrossRef]

9. Helmark, I.C.; Mikkelsen, U.R.; Børglum, J.; Rothe, A.; Petersen, M.C.; Andersen, O.; Langberg, H.; Kjaer, M. Exercise increases interleukin-10 levels both intraarticularly and peri-synovially in patients with knee osteoarthritis: A randomized controlled trial. Arthritis Res. Ther. 2010, 12, R126. [CrossRef]

10. Salter, R.B. History of Rest and Motion and the Scientific Basis for Early Continuous Passive Motion. Hand Clin. 1996, $12,1-11$. [CrossRef]

11. Roos, E.; Arden, N.K. Strategies for the prevention of knee osteoarthritis. Nat. Rev. Rheumatol. 2015, 12, 92-101. [CrossRef] [PubMed]

12. Eckstein, F.; Hudelmaier, M.; Putz, R. The effects of exercise on human articular cartilage. J. Anat. 2006, 208, 491-512. [CrossRef] [PubMed]

13. Vanwanseele, B.; Eckstein, F.; Knecht, H.; Stüssi, E.; Spaepen, A. Knee cartilage of spinal cord-injured patients displays progressive thinning in the absence of normal joint loading and movement. Arthritis Rheum. 2002, 46, 2073-2078. [CrossRef]

14. Vanwanseele, B.; Eckstein, F.; Knecht, H.; Spaepen, A.; Stüssi, E. Longitudinal analysis of cartilage atrophy in the knees of patients with spinal cord injury. Arthritis Rheumatol. 2003, 48, 3377-3381. [CrossRef] [PubMed]

15. Hinterwimmer, S.; Krammer, M.; Krötz, M.; Gläser, C.; Baumgart, R.; Reiser, M.; Eckstein, F. Cartilage atrophy in the knees of patients after seven weeks of partial load bearing. Arthritis Rheumatol. 2004, 50, 2516-2520. [CrossRef]

16. Bader, D.L.; Salter, D.M.; Chowdhury, T.T. Biomechanical Influence of Cartilage Homeostasis in Health and Disease. Arthritis 2011, 2011, 1-16. [CrossRef]

17. Millward-Sadler, S.J.; Wright, M.O.; Davies, L.W.; Nuki, G.; Salter, D.M. Mechanotransduction via integrins and interleukin-4 results in altered aggrecan and matrix metalloproteinase 3 gene expression in normal, but not osteoarthritic, human articular chondrocytes. Arthritis Rheumatol. 2000, 43, 2091-2099. [CrossRef]

18. Ikenoue, T.; Trindade, M.C.D.; Lee, M.S.; Lin, E.Y.; Schurman, D.J.; Goodman, S.B.; Smith, R.L. Mechanoregulation of human articular chondrocyte aggrecan and type II collagen expression by intermittent hydrostatic pressure in vitro. J. Orthop. Res. 2003, 21, 110-116. [CrossRef]

19. Mizuno, S.; Tateishi, T.; Ushida, T.; Glowacki, J. Hydrostatic fluid pressure enhances matrix synthesis and accumulation by bovine chondrocytes in three-dimensional culture. J. Cell. Physiol. 2002, 193, 319-327. [CrossRef]

20. Lin, P.M.; Chen, C.-T.C.; Torzilli, P.A. Increased stromelysin-1 (MMP-3), proteoglycan degradation (3B3- and 7D4) and collagen damage in cyclically load-injured articular cartilage. Osteoarthr. Cartil. 2004, 12, 485-496. [CrossRef]

21. Loening, A.; James, I.E.; Levenston, M.; Badger, A.M.; Frank, E.H.; Kurz, B.; Nuttall, M.E.; Hung, H.-H.; Blake, S.M.; Grodzinsky, A.J.; et al. Injurious Mechanical Compression of Bovine Articular Cartilage Induces Chondrocyte Apoptosis. Arch. Biochem. Biophys. 2000, 381, 205-212. [CrossRef]

22. DiMicco, M.A.; Patwari, P.; Siparsky, P.N.; Kumar, S.; Pratta, M.A.; Lark, M.W.; Kim, Y.-J.; Grodzinsky, A.J. Mechanisms and kinetics of glycosaminoglycan release following in vitro cartilage injury. Arthritis Rheum. 2004, 50, 840-848. [CrossRef]

23. Kurz, B.; Jin, M.; Patwari, P.; Cheng, D.; Lark, M.W.; Grodzinsky, A.J. Biosynthetic response and mechanical properties of articular cartilage after injurious compression. J. Orthop. Res. 2001, 19, 1140-1146. [CrossRef]

24. Smith, R.L.; Lin, J.; Trindade, M.C.D.; Shida, J.; Kajiyama, G.; Vu, T.; Hoffman, A.R.; Van Der Meulen, M.C.H.; Goodman, S.B.; Schurman, D.J.; et al. Time-dependent effects of intermittent hydrostatic pressure on articular chondrocyte type II collagen and aggrecan mRNA expression. J. Rehabil. Res. Dev. 2000, 37, 153-161. [PubMed]

25. Wong, M.; Carter, D. Articular cartilage functional histomorphology and mechanobiology: A research perspective. Bone 2003, 33, 1-13. [CrossRef]

26. Guilak, F; Mow, V.C. The mechanical environment of the chondrocyte: A biphasic finite element model of cell-matrix interactions in articular cartilage. J. Biomech. 2000, 33, 1663-1673. [CrossRef]

27. Schmidt, M.B.; Chen, E.H.; Lynch, S.E. A review of the effects of insulin-like growth factor and platelet derived growth factor on in vivo cartilage healing and repair. Osteoarthr. Cartil. 2006, 14, 403-412. [CrossRef]

28. Middleton, J.; Manthey, A.; Tyler, J. Insulin-like growth factor (IGF) receptor, IGF-I, interleukin-1 beta (IL-1 beta), and IL-6 mRNA expression in osteoarthritic and normal human cartilage. J. Histochem. Cytochem. 1996, 44, 133-141. [CrossRef] [PubMed] 
29. McQuillan, D.J.; Handley, C.J.; Campbell, M.A.; Bolis, S.; Milway, V.E.; Herington, A. Stimulation of proteoglycan biosynthesis by serum and insulin-like growth factor-I in cultured bovine articular cartilage. Biochem. J. 1986, 240, 423-430. [CrossRef]

30. Tyler, J.A. Insulin-like growth factor 1 can decrease degradation and promote synthesis of proteoglycan in cartilage exposed to cytokines. Biochem. J. 1989, 260, 543-548. [CrossRef] [PubMed]

31. Goodrich, L.R.; Hidaka, C.; Robbins, P.D.; Evans, C.H.; Nixon, A.J. Genetic modification of chondrocytes with insulin-like growth factor-1 enhances cartilage healing in an equine model. J. Bone Jt. Surg. Br. Vol. 2007, 89, 672-685. [CrossRef]

32. Morales, T. Transforming Growth Factor- $\beta$ and Insulin-like Growth Factor-1 Restore Proteoglycan Metabolism of Bovine Articular Cartilage After Depletion by Retinoic Acid. Arch. Biochem. Biophys. 1994, 315, 190-198. [CrossRef] [PubMed]

33. Neidel, J.; Schulze, M.; Sova, L. Insulin-like growth factor I accelerates recovery of articular cartilage proteoglycan synthesis in culture after inhibition by interleukin 1. Arch. Orthop. Trauma Surg. 1994, 114, 43-48. [CrossRef] [PubMed]

34. Sah, R.; Chen, A.; Grodzinsky, A.; Trippel, S. Differential Effects of bFGF and IGF-I on Matrix Metabolism in Calf and Adult Bovine Cartilage Explants. Arch. Biochem. Biophys. 1994, 308, 137-147. [CrossRef]

35. Bonassar, L.J.; Grodzinsky, A.J.; Srinivasan, A.; Davila, S.G.; Trippel, S.B. Mechanical and Physicochemical Regulation of the Action of Insulin-Like Growth Factor-I on Articular Cartilage. Arch. Biochem. Biophys. 2000, 379, 57-63. [CrossRef] [PubMed]

36. Bonassar, L.J.; Grodzinsky, A.J.; Frank, E.H.; Davila, S.G.; Bhaktav, N.R.; Trippel, S.B. The effect of dynamic compression on the response of articular cartilage to insulin-like growth factor-I. J. Orthop. Res. 2001, 19, 11-17. [CrossRef]

37. Yang, X.; Chen, L.; Xu, X.; Li, C.; Huang, C.; Deng, C.-X. TGF- $\beta$ /Smad3 Signals Repress Chondrocyte Hypertrophic Differentiation and Are Required for Maintaining Articular Cartilage. J. Cell Biol. 2001, 153, 35-46. [CrossRef]

38. Ferguson, C.M.; Schwarz, E.M.; Reynolds, P.R.; Puzas, J.E.; Rosier, R.N.; O'Keefe, R.J. Smad2 and 3 mediate transforming growth factor- $\beta 1$-induced inhibition of chondrocyte maturation. Endocrinology 2000, 141, 4728-4735. [CrossRef]

39. Kim, K.-O.; Sampson, E.R.; Maynard, R.; O’Keefe, R.J.; Chen, D.; Drissi, H.; Rosier, R.N.; Hilton, M.; Zuscik, M.J. Ski inhibits TGF- $\beta$ /phospho-Smad3 signaling and accelerates hypertrophic differentiation in chondrocytes. J. Cell. Biochem. 2012, 113, 2156-2166. [CrossRef]

40. Finnson, K.; Parker, W.L.; Dijke, P.T.; Thorikay, M.; Philip, A. ALK1 Opposes ALK5/Smad3 Signaling and Expression of Extracellular Matrix Components in Human Chondrocytes. J. Bone Miner. Res. 2008, 23, 896-906. [CrossRef]

41. Blaney Davidson, E.N.; Remst, D.F.G.; Vitters, E.L.; Van Beuningen, H.M.; Blom, A.B.; Goumans, M.-J.; Van Den Berg, W.B.; Van Der Kraan, P.M. Increase in ALK1/ALK5 Ratio as a Cause for Elevated MMP-13 Expression in Osteoarthritis in Humans and Mice. J. Immunol. 2009, 182, 7937-7945. [CrossRef]

42. Madej, W.; van Caam, A.; Davidson, E.B.; van der Kraan, P.; Buma, P. Physiological and excessive mechanical compression of articular cartilage activates Smad2/3P signaling. Osteoarthr. Cartil. 2014, 22, 1018-1025. [CrossRef] [PubMed]

43. Van Der Kraan, P.M. The changing role of TGF $\beta$ in healthy, ageing and osteoarthritic joints. Nat. Rev. Rheumatol. 2017, 13, 155-163. [CrossRef]

44. Iwanaga, H.; Matsumoto, T.; Enomoto, H.; Okano, K.; Hishikawa, Y.; Shindo, H.; Koji, T. Enhanced expression of insulin-like growth factor-binding proteins in human osteoarthritic cartilage detected by immunohistochemistry and in situ hybridization. Osteoarthr. Cartil. 2005, 13, 439-448. [CrossRef]

45. Zhu, Y.; Tao, H.; Jin, C.; Liu, Y.; Lu, X.; Hu, X.; Wang, X. Transforming growth factor- $\beta 1$ induces type II collagen and aggrecan expression via activation of extracellular signal-regulated kinase 1/2 and Smad2/3 signaling pathways. Mol. Med. Rep. 2015, 12, 5573-5579. [CrossRef] [PubMed]

46. Redini, F.; Galera, P.; Mauviel, A.; Loyau, G.; Pujol, J.-P. Transforming growth factor $\beta$ stimulates collagen and glycosaminoglycan biosynthesis in cultured rabbit articular chondrocytes. FEBS Lett. 1988, 234, 172-175. [CrossRef]

47. Galéra, P.; Vivien, D.; Pronost, S.; Bonaventure, J.; Rédini, F.; Loyau, G.; Pujol, J.-P. Transforming growth factor- $\beta 1$ (TGF- $\beta 1$ ) up-regulation of collagen type II in primary cultures of rabbit articular chondrocytes (RAC) involves increased mRNA levels without affecting mRNA stability and procollagen processing. J. Cell. Physiol. 1992, 153, 596-606. [CrossRef] [PubMed]

48. Burton-Wurster, N.; Lust, G. Fibronectin and proteoglycan synthesis in long term cultures of cartilage explants in Ham's F12 supplemented with insulin and calcium: Effects of the addition of TGF- $\beta$. Arch. Biochem. Biophys. 1990, 283, 27-33. [CrossRef]

49. Leiss, M.; Beckmann, K.; Girós, A.; Costell, M.; Fässler, R. The role of integrin binding sites in fibronectin matrix assembly in vivo. Curr. Opin. Cell Biol. 2008, 20. [CrossRef]

50. Wipff, P.-J.; Hinz, B. Integrins and the activation of latent transforming growth factor $\beta 1-$ An intimate relationship. Eur. J. Cell Biol. 2008, 87, 601-615. [CrossRef]

51. Rampersad, S.N. Multiple Applications of Alamar Blue as an Indicator of Metabolic Function and Cellular Health in Cell Viability Bioassays. Sensors 2012, 12, 12347-12360. [CrossRef] [PubMed]

52. McAlinden, A. Alternative splicing of type II procollagen: IIB or not IIB? Connect. Tissue Res. 2014, 55, 165-176. [CrossRef] [PubMed]

53. Gudmann, N.S.; Wang, J.; Hoielt, S.; Chen, P.; Siebuhr, A.S.; Mobasheri, A.; Christiansen, T.G.; Karsdal, M.A.; Bay-Jensen, A.C. Cartilage Turnover Reflected by Metabolic Processing of Type II Collagen: A Novel Marker of Anabolic Function in Chondrocytes. Int. J. Mol. Sci. 2014, 15, 18789-18803. [CrossRef] [PubMed]

54. Luo, Y.; He, Y.; Reker, D.; Gudmann, N.S.; Henriksen, K.; Simonsen, O.; Ladel, C.; Michaelis, M.; Mobasheri, A.; Karsdal, M.; et al. A Novel High Sensitivity Type II Collagen Blood-Based Biomarker, PRO-C2, for Assessment of Cartilage Formation. Int. J. Mol. Sci. 2018, 19, 3485. [CrossRef] [PubMed] 
55. Bager, C.; Gudmann, N.; Willumsen, N.; Leeming, D.; Karsdal, M.; Bay-Jensen, A.; Høgdall, E.; Balslev, I.; He, Y. Quantification of fibronectin as a method to assess ex vivo extracellular matrix remodeling. Biochem. Biophys. Res. Commun. 2016, 478, 586-591. [CrossRef]

56. Wickham, H.; Averick, M.; Bryan, J.; Chang, W.; McGowan, L.D.; François, R.; Grolemund, G.; Hayes, A.; Henry, L.; Hester, J.; et al. Welcome to the Tidyverse. J. Open Source Softw. 2019, 4, 1686. [CrossRef]

57. Searle, S.R.; Speed, F.M.; Milliken, G.A. Population Marginal Means in the Linear Model: An Alternative to Least Squares Means. Am. Stat. 1980, 34, 216-221. [CrossRef]

58. Bates, D.; Mächler, M.; Bolker, B.; Walker, S. Fitting linear mixed-effects models using lme4. R package version 1.1-8. J. Stat. Softw. 2015, 67, 1-48. [CrossRef]

59. Kuznetsova, A.; Brockhoff, P.B.; Christensen, R.H.B. lmerTest Package: Tests in Linear Mixed Effects Models. J. Stat. Softw. 2017, 82, 1-26. [CrossRef]

60. Thudium, C.S.; Engstrøm, A.; Groen, S.S.; Karsdal, M.A.; Bay-Jensen, A.-C. An Ex Vivo Tissue Culture Model of Cartilage Remodeling in Bovine Knee Explants. J. Vis. Exp. 2019, 2019, e59467. [CrossRef] [PubMed]

61. Lin, W.; Klein, J. Recent Progress in Cartilage Lubrication. Adv. Mater. 2021, 33, 2005513. [CrossRef] [PubMed]

62. Mow, V.C.; Wang, C.C.; Hung, C.T. The extracellular matrix, interstitial fluid and ions as a mechanical signal transducer in articular cartilage. Osteoarthr. Cartil. 1999, 7, 41-58. [CrossRef]

63. Lu, X.L.; Mow, V.C. Biomechanics of Articular Cartilage and Determination of Material Properties. Med. Sci. Sports Exerc. 2008, 40, 193-199. [CrossRef]

64. Fukubayashi, T.; Kurosawa, H. The Contact Area and Pressure Distribution Pattern of the Knee:A Study of Normal and Osteoarthrotic Knee Joints. Acta Orthop. Scand. 1980, 51, 871-879. [CrossRef]

65. Ahmed, A.M.; Burke, D.L. In-Vitro of Measurement of Static Pressure Distribution in Synovial Joints-Part I: Tibial Surface of the Knee. J. Biomech. Eng. 1983, 105, 216-225. [CrossRef] [PubMed]

66. Parkkinen, J.; Ikonen, J.; Lammi, M.; Laakkonen, J.; Tammi, M.; Helminen, H. Effects of Cyclic Hydrostatic Pressure on Proteoglycan Synthesis in Cultured Chondrocytes and Articular Cartilage Explants. Arch. Biochem. Biophys. 1993, 300, 458-465. [CrossRef] [PubMed]

67. Larsson, T.; Aspden, R.; Heinegård, D. Effects of Mechanical Load on Cartilage Matrix Biosynthesis In Vitro. Matrix 1991, 11, 388-394. [CrossRef]

68. Huang, C.-Y.; Gu, W.Y. Effects of Tension-Compression Nonlinearity on Solute Transport in Charged Hydrated Fibrous Tissues Under Dynamic Unconfined Compression. J. Biomech. Eng. 2006, 129, 423-429. [CrossRef]

69. Servin-Vences, R.; Moroni, M.; Lewin, G.R.; Poole, K. Direct measurement of TRPV4 and PIEZO1 activity reveals multiple mechanotransduction pathways in chondrocytes. eLife 2017, 6, e21074. [CrossRef]

70. He, Z.; Leong, D.; Zhuo, Z.; Majeska, R.; Cardoso, L.; Spray, D.; Goldring, M.; Cobelli, N.; Sun, H. Strain-induced mechanotransduction through primary cilia, extracellular ATP, purinergic calcium signaling, and ERK1/2 transactivates CITED2 and downregulates MMP-1 and MMP-13 gene expression in chondrocytes. Osteoarthr. Cartil. 2016, 24, 892-901. [CrossRef]

71. Jablonski, C.L.; Ferguson, S.; Pozzi, A.; Clark, A.L. Integrin $\alpha 1 \beta 1$ participates in chondrocyte transduction of osmotic stress. Biochem. Biophys. Res. Commun. 2014, 445, 184-190. [CrossRef] [PubMed]

72. Zhang, L.; Smith, D.; Gardiner, B.S.; Grodzinsky, A.J. Modeling the Insulin-Like Growth Factor System in Articular Cartilage. PLoS ONE 2013, 8, e66870. [CrossRef]

73. Morales, T.; Joyce, M.; Sobel, M.; Danielpour, D.; Roberts, A. Transforming growth factor- $\beta$ in calf articular cartilage organ cultures: Synthesis and distribution. Arch. Biochem. Biophys. 1991, 288, 397-405. [CrossRef]

74. Bougault, C.; Aubert-Foucher, E.; Paumier, A.; Perrier-Groult, E.; Huot, L.; Hot, D.; Duterque-Coquillaud, M.; Mallein-Gerin, F. Dynamic Compression of Chondrocyte-Agarose Constructs Reveals New Candidate Mechanosensitive Genes. PLoS ONE 2012, 7, e36964. [CrossRef]

75. Zhen, G.; Guo, Q.; Li, Y.; Wu, C.; Zhu, S.; Wang, R.; Guo, X.E.; Kim, B.C.; Huang, J.; Hu, Y.; et al. Mechanical stress determines the configuration of TGF $\beta$ activation in articular cartilage. Nat. Commun. 2021, 12, 1-16. [CrossRef] [PubMed]

76. Fontana, L.; Chen, Y.; Prijatelj, P.; Sakai, T.; Fässler, R.; Sakai, L.Y.; Rifkin, D.B. Fibronectin is required for integrin o:v $\beta 6$-mediated activation of latent TGF- $\beta$ complexes containing LTBP-1. FASEB J. 2005, 19, 1798-1808. [CrossRef]

77. Gene, A.H. Potential regulation of cartilage metabolism in osteoarthritis by fibronectin fragments. Front. Biosci. 1999, 4, D713-D730. [CrossRef] 